\title{
Tuberculosis in Sheltered Homeless Population of Rome: An Integrated Model of Recruitment for Risk Management
}

\author{
Patrizia Laurenti, ${ }^{1}$ Stefania Bruno, ${ }^{1}$ Gianluigi Quaranta, ${ }^{1}$ Giuseppe La Torre, ${ }^{2}$ \\ Antonio G. Cairo, ${ }^{1}$ Pierangela Nardella, ${ }^{1}$ Giovanni Delogu, ${ }^{3}$ Giovanni Fadda, ${ }^{3}$ \\ Tommaso Pirronti, ${ }^{4}$ Salvatore Geraci, ${ }^{5}$ Salvatore Pelargonio, ${ }^{6}$ Francesco N. Lauria, ${ }^{7}$ \\ Delia Goletti, ${ }^{7}$ and Gualtiero Ricciardi ${ }^{1}$ \\ ${ }^{1}$ Department of Hygiene, Università Cattolica del Sacro Cuore, Largo Francesco Vito, 00168 Rome, Italy \\ ${ }^{2}$ Department of Public Health and Infectious Diseases, Sapienza University of Rome, Piazzale Aldo Moro, 00185 Rome, Italy \\ ${ }^{3}$ Department of Microbiology, Università Cattolica del Sacro Cuore, Largo Francesco Vito, 00168 Rome, Italy \\ ${ }^{4}$ Department of Radiologic Sciences, Università Cattolica del Sacro Cuore, Largo Francesco Vito, 00168 Rome, Italy \\ ${ }^{5}$ Caritas Health Service, Via Marsala, 00185 Rome, Italy \\ ${ }^{6}$ Acisel Day Centre, Via Verzuolo, 00166 Rome, Italy \\ ${ }^{7}$ National Institute of Infectious Diseases, Lazzaro Spallanzani, Via Portuense, 00149 Rome, Italy
}

Correspondence should be addressed to Patrizia Laurenti, plaurenti@rm.unicatt.it

Received 25 October 2011; Accepted 13 December 2011

Academic Editor: Terri L. Meinking

Copyright (C) 2012 Patrizia Laurenti et al. This is an open access article distributed under the Creative Commons Attribution License, which permits unrestricted use, distribution, and reproduction in any medium, provided the original work is properly cited.

\begin{abstract}
The authors show the results of an integrated model for risk management of tuberculosis in a sample of sheltered homeless in Rome. Tuberculin skin test (TST) was used for evaluating the prevalence of latent infection (LTBI). In TST positives, expectorate was collected and chest X-ray was achieved. Multiple logistic regression analysis was performed to investigate determinants of infection. Out of 288 recruited subjects, 259 returned for the TST reading; $45.56 \%$ were positive and referred to a specialized center; 70 accessed the health facility and completed the clinical pathway. The risk factors associated to LTBI were male gender $(\mathrm{OR}=3.72)$, age over 60 years $(\mathrm{OR}=3.59)$, immigrant status $(\mathrm{OR}=3.73)$, and obesity $(\mathrm{OR}=2.19)$. This approach, based on an integrated social network, guarantees high adherence to screening $(89.93 \%)$, allowing patients testing positive for latent tuberculosis infection to be diagnosed and rapidly referred to a specialized center.
\end{abstract}

\section{Introduction}

Together with other social factors, homelessness is one of the greatest risk factors for the acquisition of latent tuberculosis infection (LTBI) and active Tuberculosis (TB) [1]. In recent years, a few surveys have been carried out in Europe to evaluate the LTBI and TB prevalence in homeless people: the existing data (Rotterdam 29\%, London 0.5\%) show that adequate screenings and treatment pathways are needed to reduce the spread of Mycobacterium tuberculosis in overcrowded shelters and in the community $[2,3]$.

In Italy, the incidence is extremely low in the general population. In 2008, crude incidence rate was 3.8/100,000 for those born in Italy and 50-60/100,000 for those born abroad. In recent years, the incidence of pulmonary tuberculosis seems stable and around 5-6 cases per 100,000 residents. However, the concentration of the majority of TB cases was observed among certain risk groups: alcohol abusers and drug users, homeless people, HIV-infected people, and young migrants [4-6].

In Rome, in the time period 1996-2007, an annual average of $382.5 \mathrm{~TB}$ cases were notified (11.55\% of the total notified in Italy). In spite of a decreasing trend from 1996 to 1999, in the years 2006 and 2007, the trend is again increasing, with an annual average of 448.5 cases, corresponding to a rate of about 16.6/100.00 population (Figure 1) [7]. 
TB cases notified in Rome, 1996-2007

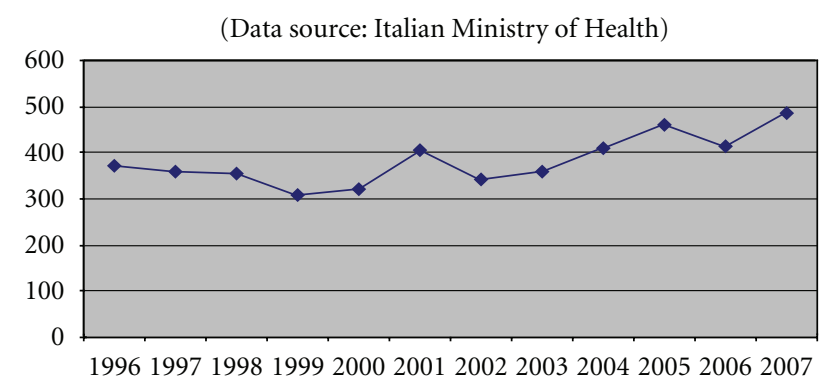

FIGURE 1: Linear diagram showing TB cases notified in Rome in the time-period 1996-2007 (source of the data: [7]).

A considerable increase of people living on the road has been reported in recent years: in 1998, a figure of 5,000 homeless people was estimated in Rome, but nowadays the expected number is about 23,000 [8], and the numbers alone could probably be a contributing factor explaining the increased rate of TB cases reported in the period 2002-2005 (409 cases in 2004 and 460 cases in 2005, up from 341 in 2002).

Epidemiological studies of homeless populations have reported the prevalence rate of $1.2 \%-6.8 \%$ for active TB [ 9 , 10]. No data about the incidence of TB in homeless people are to date available in Rome.

Better understanding of the characteristics of homeless people with TB disease is important for creating strategies to reduce TB incidence in this high-risk population [11].

Based on these assumptions, we enrolled homeless people from two shelters in Rome. A cross-sectional study was carried on with the following aims:

(1) to assess acceptance to came back for TST reading in a sample of homeless people recruited from two shelters in Rome (subjects who returned for Tuberculin Skin Test (TST) reading, after 72 hours),

(2) to measure the prevalence of skin-positive results, assumed as LTBI,

(3) to investigate the associations between social risk factors and TST positive results,

(4) to evaluate the access to a public specialized outpatient clinic for initiating an early therapeutic pathway.

\section{Methods}

The protocols of this research were cleared by the local ethical committee.

2.1. Population and Setting. The eligible individuals-male and female, Italians and foreigners, adults $\geq 18$ years oldwere recruited from two homeless refuges in Rome (named Caritas and Acisel) in the time period November 2006November 2007.

These two shelters were selected by convenience among all the others in Rome. Individuals were recruited according to HUD (US Department of Housing and Urban Development) homeless definition, as "an individual who lacks a fixed, regular,..., and adequate night-time residence..." [12].

The sample size was calculated using 2004 available data, the most recent ones existing when the protocol of the study was drafted, taking into account the homeless number in Rome, fixing the confidence level at 95\%, estimating the LTBI prevalence as $25 \%$, and considering a $90 \%$ study compliance. According to these parameters, 276 individuals were eligible to be recruited.

A detailed anamnesis was collected using a form to record data about markers and risk factors: gender, age, height, and weight (for body mass index (BMI)), origin, past TB diagnosis and therapy, immigration condition (both irregular an regular condition, without and with National health assistance, resp.), smoking habits, alcohol abuse (according to Diagnostic and Statistical Manual of Mental Disorders (DSMIV)) and drugs use.

Previous Bacillus Calmette Guerin (BCG) vaccination was investigated, with a specific question and an inspection verifying the presence of any scar on the deltoid muscle.

2.2. TST and Other Laboratory Tests. The TST (Biocine test PPD 5 UI) was performed by medical physicians in the surgery at the refuges, after informing the subjects about the study and obtaining their understanding and written consent by a translated form.

TST was read after 72 hours. According to the American Thoracic Society standards, which have provided new recommendations for targeted tuberculin testing and treatment regimens for persons with latent tuberculosis infections (LTBI), a reaction with an induration diameter $>10 \mathrm{~mm}$ and with normal chest X-ray was considered as positive and we classified this as LTBI to send the subject towards a clinical pathway, managed by a specialized hospital [13].

Only positive subjects were invited to undertake a chest $\mathrm{X}$-ray and to provide three sputum samples on alternate days. The chest X-ray was performed with an MPX+ (GE Healthcare, Italy) portable equipment for radiography and read by two different radiologists. The sputum was collected with a safe disposable device (Sputum Collection System, Becton Dickinson, USA).

The bacterioscopic examination (Ziehl-Nielsen staining) and cultures in solid (Lowenstein-Jensen) and liquid media (an automatic system MGIT, Becton Dickinson, USA), were performed by the Microbiology Unit, according to internal QC procedures.

Moreover, PCR was prepared to identify and confirm $M$. tuberculosis (Probetec, Becton Dickinson, USA).

In the case of M. tuberculosis isolates, a phenotypic study of drug resistance to streptomycin, isoniazid, ethambutol, and rifampicin and the genetic typing with random amplification of primers designed technique (RAPD), based on PCR technique, was prepared.

The positive subjects to TST were referred to INMI (National Institute for Infectious Diseases "Lazzaro Spallanzani") in Rome for clinical evaluation. 
2.3. Statistical Analysis. Univariate analysis by logistic regression was performed using the chisquare test and the MannWhitney test for assessing differences between groups for categorical and quantitative variables, respectively.

A multivariate analysis was performed using the dichotomous variable LTBI risk as the dependent variable and the following variables as independent variables: gender (female as reference group), marital status (single as reference group), nationality (foreigners as reference group), nutritional status (no obesity as reference group), and age category (age under 60 as reference group). The results are presented as odds ratios (OR) and 95\% confidence intervals (95\% CI).

A stepwise approach (backward elimination procedure) was followed, using the method suggested by Hosmer and Lemeshow. The variables were excluded from the model until a $P$ value $>0.10$. The goodness of fit of the model was assessed using the Hosmer and Lemeshow test.

The statistical significance was set at $P \leq 0.05$.

The statistical analysis was conducted using SPSS software (release 12.0).

\section{Results}

From the two homeless shelters, 288 subjects were recruited; for each subject, a data collection form was filled in and a TST performed. In the same period, 133 expectorates were collected and 46 chest X-rays performed. Among all recruited subjects, 259 came back for the TST reading, with an acceptance rate of $89.93 \%$. Of these, 204 subjects $(78.8 \%)$ were males and $55(21.2 \%)$ females; 31 (12\%) were over 60 years old. As far as marital status, 122 subjects (47.1\%) were single, $68(26.2 \%)$ married, $51(19.7 \%)$ divorced or separated, and 16 (6.2\%) widows/widowers (Table 1).

Regarding the social features, $171(66 \%)$ were immigrants and $65(25.1 \%)$ were employed during the recruitment period. Among them, 108 (41.7\%) declared to be registered within the Italian National Health Service, while $17(2.7 \%)$ reported to be foreigners temporarily present. Regarding educational level, 13 (5\%) had no education title, 124 (47.9\%) had completed Primary school, 102 (39.4\%) had completed Secondary school, and 12 (4.6\%) were graduates.

Four subjects (1.5\%) reported a previous TB diagnosis. Regarding the smoking habit, 147 (56.8\%) were smokers, 99 (38.2\%) nonsmokers, and 13 (5\%) former smokers.

Twenty-two individuals (8.5\%) declared to be alcohol abusers and 10 (3.9\%) exalcohol abusers. Most of the participants declared not to be illicit drug users, though three subjects $(1.1 \%)$ declared to be drug-users and $8(3.1 \%)$ exdrug users.

Out of the 259 compliant subjects, 141 (54.44\%) were TST negative and $118(45.56 \%)$ were positive, therefore suffering from LTBI. Among these, 18 (15.4\%) were over 60 years old, $16(13.6 \%)$ were females and $102(86.4 \%)$ were males.

No chest X-ray, sputum, and culture sample was positive, respectively, for TB and Mycobacterium tuberculosis.
In Table 2, the results of TST and the native land are reported: most people were Italians (33.2\%) and Romanians $(32 \%)$, as regards the TST positives, $27.1 \%$ were Italians and $39.8 \%$ Romanians.

All TST-positive subjects were referred to a specialized outpatient clinic and 70 of them (59,32\%) accessed the health facility and completed the diagnostic pathway to receive the appropriate therapy.

The other 48 were lost to the study because of their homelessness condition, as all homeless were not stably residential in the shelter.

One subject $(3.86 \%$ ) showed clinical suspicion of active disease and was promptly referred to hospital.

The results for LTBI risk, according to the multiple logistic regression analysis performed in order to discover the relationship with the risk factors, are shown in Table 3. Immigrant status, male gender, older age (over 60 years), and obesity were significant risk factors for developing LTBI, as shown from the OR and CI values.

\section{Discussion and Conclusions}

In large European metropolitan areas, for example, in London [14], in Rotterdam [4], in Marseilles [15], and in the Warminsko-Mazurskie Province of Poland [16], a high prevalence of $\mathrm{Tb}$ was still observed in homeless people.

Immigration, under-nutrition [17], smoking [18], diabetes [19], and alcohol misuse [20] are individual risk factors that can double or triple the risk of active TB development and all these conditions are often associated with homelessness.

In these perspectives, the results of our study indicate a prevalence of LTBI of $45.56 \%$ among the homeless and of $3.86 \%$ for active TB.

The low rate of active TB, compared to cited experiences, could be interpreted as a sign of protection and full immunecompetence of this group of subjects. It may be hypothesised that the incidence of active TB in this cohort of LTBI-positive homeless persons may be explained by the good quality of conditions available for the homeless living in Italian shelters, which warrant good nutritional status and, therefore, low risk of progression to active disease. Nevertheless, the remarkably high LTBI prevalence observed may indicate that the homeless may have a higher risk of contracting $M$. tuberculosis infection because of overcrowded environments or because they shelter in a community where the greater chance of an active TB patient transmitting the microorganism is not promptly recognized.

In this perspective, finally, immigrants should not be considered as spreaders of the disease but as persons at risk, and appropriate public health approaches should be oriented towards them, aimed at inclusion and at the promotion of barrier-free prevention and care measures [21].

In Italy, health is a constitutional right for everyone, migrants included, independent of their judicial condition. Nevertheless, in practice, a high level of inequality affects access to healthcare services, as this is noted when we compare the Italian population with migrants. Available data 
TABLE 1: Characteristics of participants according to the TST result.

\begin{tabular}{|c|c|c|c|}
\hline Variable & $\mathrm{TST}+N(\%)$ & TST $-N(\%)$ & $P$ \\
\hline \multicolumn{4}{|l|}{ Gender } \\
\hline Male & $102(50)$ & $102(50)$ & \multirow{2}{*}{0.006} \\
\hline Female & $16(29.1)$ & $39(70.9)$ & \\
\hline \multicolumn{4}{|l|}{ Age (years) } \\
\hline$<60$ & $99(43.8)$ & $127(56.2)$ & \multirow{2}{*}{0.135} \\
\hline$\geq 60$ & $18(58.1)$ & $13(41.9)$ & \\
\hline \multicolumn{4}{|l|}{ Marital status } \\
\hline Single & $49(40.2 \%)$ & $73(59.8 \%)$ & \multirow{4}{*}{0.158} \\
\hline Married & $38(55.9 \%)$ & $30(44.1 \%)$ & \\
\hline Divorced or separated & $22(43.1 \%)$ & $29(56.9 \%)$ & \\
\hline Widowers & $9(56.2 \%)$ & $7(43.8 \%)$ & \\
\hline \multicolumn{4}{|l|}{ Immigrant } \\
\hline Yes & $85(49.7 \%)$ & $86(50.3 \%)$ & \multirow{2}{*}{0.062} \\
\hline No & $33(37.5 \%)$ & $55(62.5 \%)$ & \\
\hline \multicolumn{4}{|c|}{ Italian National Health Service } \\
\hline No & $59(46.5 \%)$ & $68(53.5 \%)$ & \multirow{3}{*}{0.831} \\
\hline Yes & $47(43.5 \%)$ & $61(56.5 \%)$ & \\
\hline Unknown & $1(33.3 \%)$ & $2(66.7 \%)$ & \\
\hline \multicolumn{4}{|c|}{ Temporary Present Foreigners } \\
\hline No & $31(49.2)$ & $32(50.8)$ & \multirow{3}{*}{0.473} \\
\hline Yes & $7(41.2)$ & $10(58.8)$ & \\
\hline Not Known & $3(75)$ & $1(25)$ & \\
\hline \multicolumn{4}{|l|}{ Educational level } \\
\hline No instruction title & $5(38.5)$ & $8(61.5)$ & \multirow{4}{*}{0.585} \\
\hline Primary school & $54(43.5)$ & $70(56.5)$ & \\
\hline Secondary school & $51(50)$ & $51(50)$ & \\
\hline Degree & $5(33.3)$ & $7(66.7)$ & \\
\hline \multicolumn{4}{|l|}{ Employment } \\
\hline No & $86(44.6)$ & $107(55.4)$ & \multirow{2}{*}{0.661} \\
\hline Yes & $31(47.7)$ & $34(52.3)$ & \\
\hline \multicolumn{4}{|l|}{ Previous TBC diagnosis } \\
\hline No & $114(46.2)$ & $133(53.8)$ & \multirow{2}{*}{0.115} \\
\hline Yes & $3(75)$ & $1(25)$ & \\
\hline \multicolumn{4}{|l|}{ Smoking habit } \\
\hline No smoker & $42(42.4)$ & $57(57.6)$ & \multirow{3}{*}{0.328} \\
\hline Smoker & $72(49)$ & $75(51)$ & \\
\hline Former smoker & $4(30.8)$ & $9(69.2)$ & \\
\hline \multicolumn{4}{|l|}{ Alcohol abuse } \\
\hline No & $98(44.3)$ & $123(55.7)$ & \multirow{3}{*}{0.743} \\
\hline Yes & $11(52.4)$ & $10(47.6)$ & \\
\hline Exalcohol abuser & $5(50)$ & $5(50)$ & \\
\hline \multicolumn{4}{|l|}{ Illicit drug use } \\
\hline No & $105(45.5)$ & $126(54.5)$ & \\
\hline Yes & $1(33.3)$ & $2(66.7)$ & 0.833 \\
\hline Former drug user & $3(37.5)$ & $5(62.5)$ & \\
\hline Obesity & & & \\
\hline No & $87(42.9)$ & $116(57.1)$ & 0096 \\
\hline Yes & $30(55.6)$ & $24(44.4)$ & 0.096 \\
\hline
\end{tabular}


TABLE 2: Results of the TST by the native land.

\begin{tabular}{lccc}
\hline Native Land & No. of subjects & TST $+N(\%)$ & TST $-N(\%)$ \\
\hline Italy & 86 & $32(37.2)$ & $54(62.8)$ \\
Romania & 83 & $47(56.6)$ & $36(43.4)$ \\
Afghanistan & 22 & $9(40.9)$ & $13(59.1)$ \\
Eritrea & 14 & $6(42.9)$ & $8(57.1)$ \\
Others & 54 & $24(44.4)$ & $30(55.6)$ \\
\hline Total & 259 & $118(45.6)$ & $141(54.4)$ \\
\hline
\end{tabular}

TABLE 3: Results of the multivariate approach performed in order to find statistically significant determinants of LTBI. (OR: Odds Ratio; CI: Confidence Interval).

\begin{tabular}{|c|c|c|}
\hline & $\begin{array}{c}\text { Univariate analysis } \\
\text { OR }(95 \% \mathrm{CI})\end{array}$ & $\begin{array}{l}\text { Multivariate analysis } \\
\text { OR }(95 \% \mathrm{CI})\end{array}$ \\
\hline \multicolumn{3}{|l|}{ Native land } \\
\hline African (referent) & 1 & \\
\hline Eastern Mediterranean & $0.68(0.22-2.16)$ & \\
\hline Europe & $1.42(0.51-3.94)$ & \\
\hline America or Asia or Western Pacific & $0.27(0.04-1.90)$ & \\
\hline \multicolumn{3}{|l|}{ Gender } \\
\hline Female & 1 & 1 \\
\hline Male & $5.06(2.29-11.17)$ & $3.72(1.83-7.58)$ \\
\hline \multicolumn{3}{|l|}{ Age group } \\
\hline$<60$ years & 1 & 1 \\
\hline$\geq 60$ years & $3.64(1.40-9.51)$ & $3.59(1.40-9.21)$ \\
\hline \multicolumn{3}{|l|}{ Immigrant status } \\
\hline No & 1 & 1 \\
\hline Yes & $5.13(2.15-12.25)$ & $3.73(1.89-7.39)$ \\
\hline \multicolumn{3}{|l|}{ Employment } \\
\hline No & 1 & \\
\hline Yes & $1.00(0.52-1.94)$ & \\
\hline \multicolumn{3}{|l|}{ Obesity } \\
\hline No & 1 & 1 \\
\hline Yes & $1.91(0.93-3.91)$ & $2.19(1.10-4.35)$ \\
\hline \multicolumn{3}{|l|}{ Education } \\
\hline Lower (primary school) & 1 & \\
\hline High (secondary school or degree) & $0.84(0.52-1.35)$ & \\
\hline \multicolumn{3}{|l|}{ Marital status } \\
\hline Single & 1 & \\
\hline Married & $1.81(0.91-3.61)$ & \\
\hline Divorced, separated, or widowers & $1.63(0.77-3.43)$ & \\
\hline
\end{tabular}

reveal a substantial failure of health and social policies for integration [22].

In 2008, European Centre for Disease Control (ECDC) published a framework action plan to fight TB in the European Union (EU), which recognizes the concentration of TB in "hard to find" and "hard to treat" populations as a major challenge to TB control efforts across the EU and encourages EU institutions to collaborate with partners to identify and disseminate good practice models for TB control [23].
On these foundations, our study applies this model of TB control in advance and for the first time in Rome and produced a high compliance amongst the homeless population. In fact, a high adherence to screening was observed $(89.93 \%)$ if compared with a $65 \%$ adherence to TST reading registered in a preventive therapy programe carried out in an inner city population in Atlanta in 1994-1996 [24] and with a maximum adherence rate of $84 \%$ using economic incentive strategy to encourage test reading adherence in a high-risk population [25]. 
Our data confirm that active surveillance is an excellent tool for prevention. Active research in crowded areas gave the possibility to $59.32 \%$ of the positive subjects to access health care facilities and to complete the clinical pathway.

The strength of our experience was the opportunity to reach people in shelters (where people sleep and eat) and to start a clinical activity within the same place, with highly motivated staff, in order to facilitate access by the most disadvantaged persons.

Nevertheless, the compliance to the TST reading decreased from $89.93 \%$ to a $59.32 \%$ clinical compliance when health and social support was missing and people were invited to go to hospital by themselves. The active role of a social network also should be strengthened with the aims of prevention, diagnosis, treatment, and followup. For example, the Dutch TB control model is based on close collaboration between hospitals and municipal public health TB [23].

Moreover, guidelines should take into account the peculiarities of risk groups for whom health is not a priority [26].

Study Limitations. Firstly, concerning internal validity, a possible bias could have been introduced by a $10 \%$ of refusal to come back for the test reading.

In any case, persons who came back for TST reading are substantially similar to the ones who did not regarding two important variables: age $(P=0.639)$ and gender $(P=$ 0.718 ). As such, we expect that subjects who did not return for a TST reading did not influence the statistical analysis.

Secondly, some aspects could also affect external validity. In fact, the homeless evaluated were recruited in two shelters in Rome and this aspect could represent an important issue for the generalization of this study's results to the whole Italy. Perhaps the study's findings may not be generalized to all homeless shelters in Rome because the socio-demographic and socio-economic characteristics of homeless people living in the other shelters are unknown.

A further limit of our study could be related to the impossibility to use the latest interferon gamma release assays (IGRAs) because of blood sampling difficulties in the studied population, that would have been useful in the diagnosis of recent infection.

Lastly, atypical infection and effects of the BCG used in the country may impact on the results of TST.

\section{Acknowledgments}

This study has been supported by the Italian Ministry of Education, University and Research (PRIN 2005 no. 2005060582). All authors read and approved the final manuscript and permit editing of the paper for readability.

\section{References}

[1] B. W. Higgs, M. Mohtashem, J. Grinsdale, and L. M. Kawamura, "Early detection of tuberculosis outbreaks among the San Francisco homeless: trade-offs between spatial resolution and temporal scale," PLoS One, vol. 2, no. 12, Article ID e1284, 2007.

[2] G. De Vries and R. A. Van Hest, "From contact investigation to tuberculosis screening of drug addicts and homeless persons in Rotterdam," European Journal of Public Health, vol. 16, no. 2, pp. 133-136, 2006.

[3] A. Story, S. Murad, W. Roberts, M. Verheyen, and A. C. Hayward, "Tuberculosis in London: The importance of homelessness. problem drug use and prison," Thorax, vol. 62, no. 8 , pp. 667-671, 2007.

[4] Ministry of Health Italy, November, 2009, http://www.salute .gov.it/imgs/C_17_pubblicazioni_613_allegato.pdf.

[5] Ministry of Health Italy, "Rapporto "La tubercolosi in Italia anno 2008'," http://www.salute.gov.it/imgs/C_17_pubblicazioni_1222_allegato.pdf.

[6] Epicentro Istituto Superiore di Sanità, http://www.epicentro .iss.it/problemi/Tubercolosi/epid.asp.

[7] "Bollettino Epidemiologico-Ministero della Salute," http:// www.salute.gov.it/.

[8] La quarta capitale, http://www.roma-capitale.it/documenti/ laquartacapitale.pdf.

[9] S. Badiaga, D. Raoult, and P. Brouqui, "Preventing and controlling emerging and reemerging transmissible diseases in the homeless," Emerging Infectious Diseases, vol. 14, no. 9, pp. 1353-1359, 2008.

[10] M. B. Haddad, T. W. Wilson, K. Ijaz, S. M. Marks, and M. Moore, "Tuberculosis and homelessness in the United States, 1994-2003," Journal of the American Medical Association, vol. 293, no. 22, pp. 2762-2766, 2005.

[11] Center for Diseases Control, "Tuberculosis transmission in a homeless shelter population-New York, 2000-2003," Morbidity and Mortality Weekly Report, vol. 54, no. 6, pp. 149-152, 2005.

[12] Department of Housing and Urban Development, "Federal definition of Homeless/U.S.," http://www.hud.gov/homeless/ definition.cfm.

[13] American Thoracic Society, "Targeted Tuberculin testing and treatment of latent tuberculosis infection," Morbidity and Mortality Weekly Report, vol. 49, no. RR-6, pp. 1-51, 2000.

[14] Health Protection Agency, Focus on tuberculosis: annual surveillance report 2005-England, Wales and Northern Ireland, Health Protection Agency Centre for Infections, London, UK, 2006.

[15] S. Badiaga, H. Richet, P. Azas et al., "Contribution of a shelterbased survey for screening respiratory diseases in the homeless," European Journal of Public Health, vol. 19, no. 2, pp. 157$160,2009$.

[16] J. Romaszko, A. Buciński, R. Wasiński, A. Rosłan, and K. Bednarski, "Incidence and risk factors for pulmonary tuberculosis among the poor in the northern region of Poland," International Journal of Tuberculosis and Lung Disease, vol. 12, no. 4, pp. 430-435, 2008.

[17] K. Lönnroth, B. G. Williams, P. Cegielski, and C. Dye, "A consistent log-linear relationship between tuberculosis incidence and body mass index," International Journal of Epidemiology, vol. 39, no. 1, pp. 149-155, 2010.

[18] K. Slama, C. Y. Chiang, D. A. Enarson et al., "Tobacco and tuberculosis: a qualitative systematic review and meta-analysis," International Journal of Tuberculosis and Lung Disease, vol. 11, no. 10, pp. 1049-1061, 2007.

[19] K. E. Dooley and R. E. Chaisson, "Tuberculosis and diabetes mellitus: convergence of two epidemics," The Lancet Infectious Diseases, vol. 9, no. 12, pp. 737-746, 2009. 
[20] J. Rehm, A. V. Samokhvalov, M. G. Neuman et al., “The association between alcohol use, alcohol use disorders and tuberculosis (TB). A systematic review," BMC Public Health, vol. 9, article no. 450, 2009.

[21] Saluteinternazionale.info, "Politiche efficaci per contrastare la tubercolosi negli immigrati: le raccomandazioni degli esperti," http://saluteinternazionale.info/2010/03/politiche-efficaciper-contrastare-la-tubercolosi-negli-immigrati-le-raccomandazioni-degli-esperti/.

[22] S. F. Bonati, "Laboratorio per la Salute Materno Infantile Dipartimento di Salute Pubblica, IRFMN Milano," http:// www.simmweb.it/fileadmin/documenti/Simm_x_news/2010/ 4-2010_R_P.pdf.

[23] R. van Hest and A. Story, "Tuberculosis control in homeless persons in European Union: more than words alone," Pneumologia, vol. 58, no. 2, pp. 84-87, 2009.

[24] N. N. Bock, B. S. Metzger, J. R. Tapia, and H. M. Blumberg, "A tuberculin screening and isoniazid preventive therapy program in an inner-city population," American Journal of Respiratory and Critical Care Medicine, vol. 159, no. 1, pp. 295300, 1999.

[25] T. L. Cheng, M. C. Ottolini, K. Baumhaft, C. Brasseux, M. D. Wolf, and P. C. Sheidt, "Strategies to increase adherence with tuberculosis test reading in a high-risk population," Pediatrics, vol. 100, no. 2, pp. 210-213, 1997.

[26] S. Geraci, S. Casagrande, and A. Spagnolo, La salute degli Immigrati: una Salute di Tutti, Caritas, Roma, Italy, 2010. 


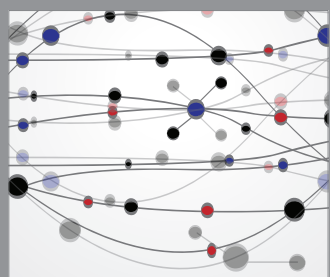

The Scientific World Journal
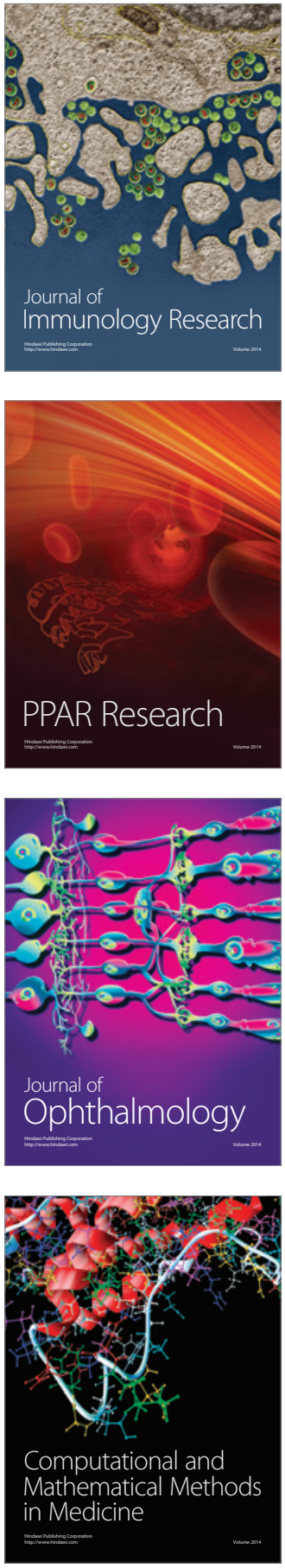

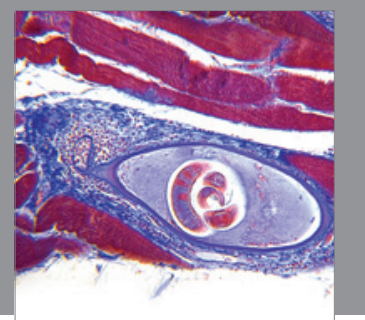

Gastroenterology

Research and Practice
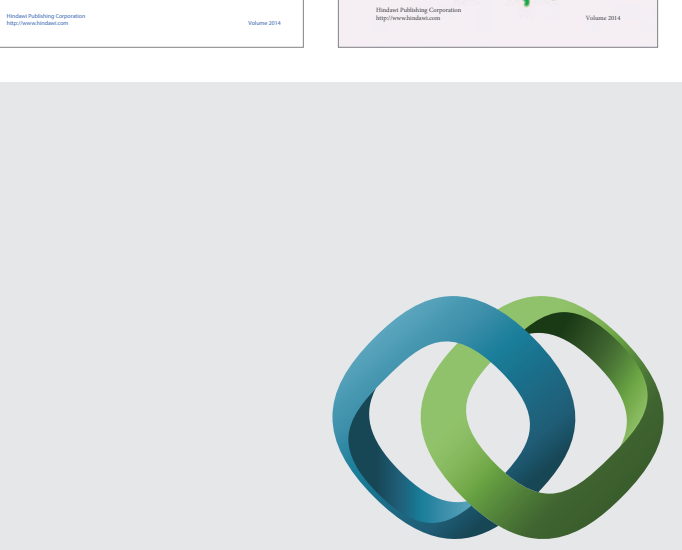

\section{Hindawi}

Submit your manuscripts at

http://www.hindawi.com
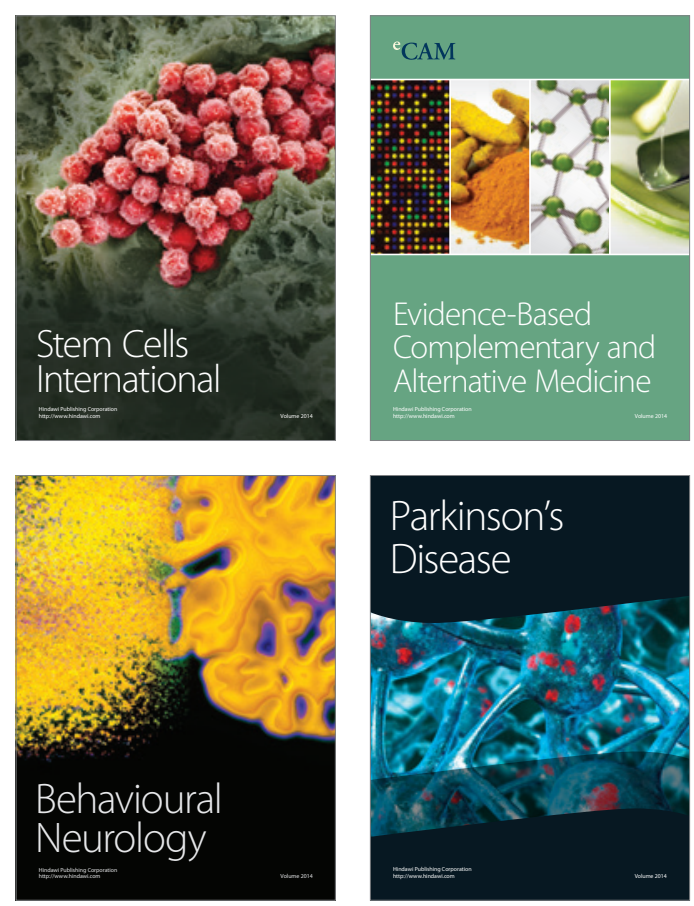

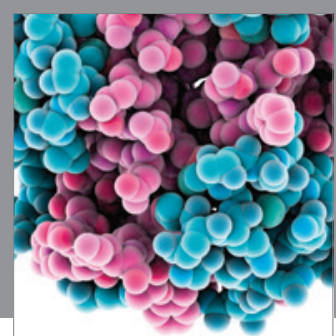

Journal of
Diabetes Research

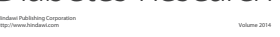

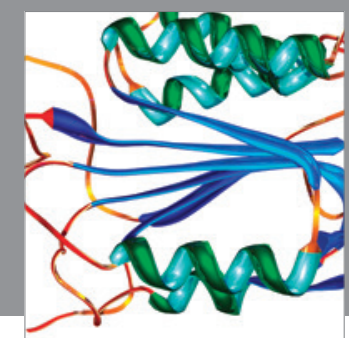

Disease Markers
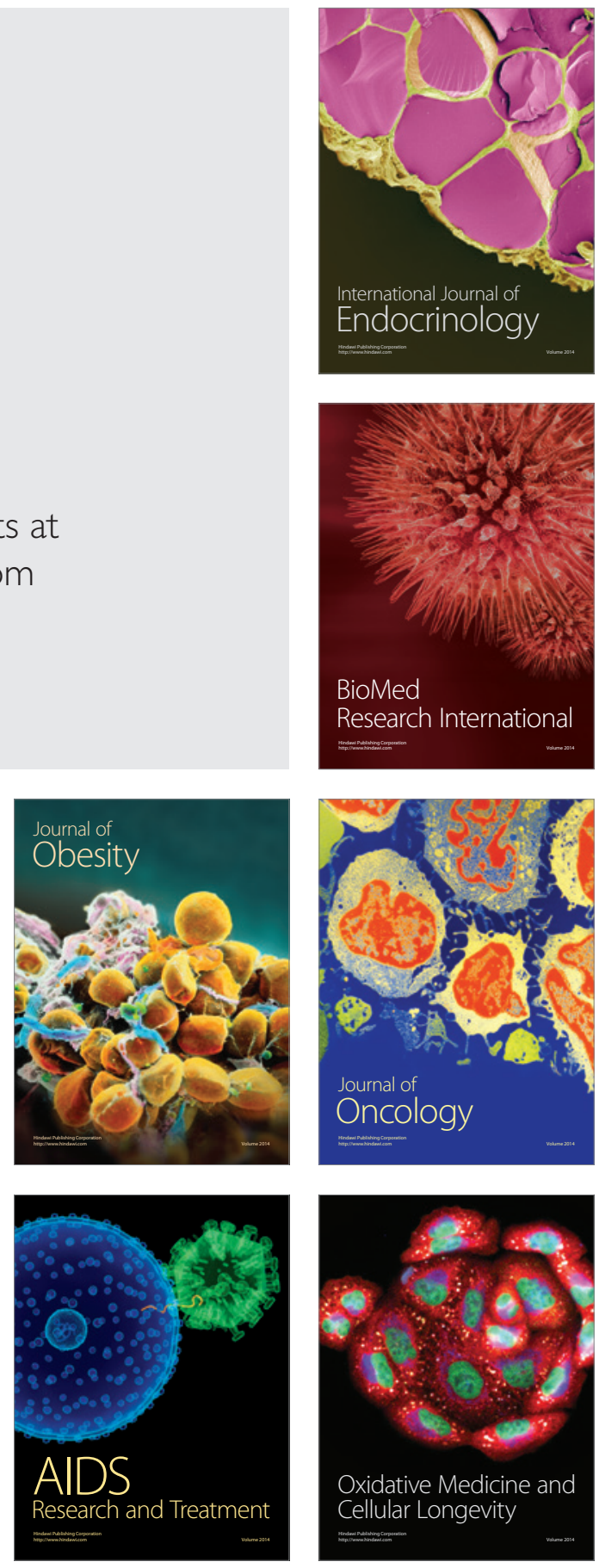